\title{
Understanding Nurses' Intentions to Respond to Requests for Assisted Dying
}

\author{
Michael Wilson* \\ Faculty of Health and Medical Sciences (Nursing), University of Adelaide, Australia
}

\begin{abstract}
The trajectory of nursing research since the early 1990s has provided rich information about nursing attitudes toward medically assisted dying (AD) and willingness to participate with it. The research has focussed on a rare event and is usually fragmented by national jurisdictions and methodological inconsistencies that make normative conclusions nearly impossible. Despite the richness of this information, its explanatory power is diminished because it focuses on willingness to participate, not what nurses intend to do. This deficit arises from the theoretical nature of the research that cannot model the factors that predict behaviour. This paper acknowledges the emergence of new $\mathrm{AD}$-related research drawn from behavioural science that models predictive factors. The relevance of nursing research in this area can be further enhanced by a pivot away from rare events of euthanasia to the increasingly frequent need to respond to a patient's request for $\mathrm{AD}$.
\end{abstract}

KEYWORDS: Nursing research; Euthanasia; Assisted-dying; Behavioural theory; Theory of planned Behaviour

ABBREVIATIONS: AD: Assisted Dying; TPB: Theory of Planned Behaviour

\section{INTRODUCTION}

The early reviews of research into nurses' experiences with medically assisted dying (AD) emerged in the early 1990s, coinciding with the beginning of legislative discussions that eventually legalised a form of AD in Oregon, and in Australia's Northern Territory [1-4]. The focus of this research was on nurses' views about legalisation of $\mathrm{AD}$, its ethical acceptability, and their willingness to participate in the 'an act of euthanasia'. Nursing research in the area of $\mathrm{AD}$ since then has continued examining these concerns [5], providing a rich information base about the demographic correlates and qualitative data related to attitudes toward this controversial service. This information suffers from a lack of comparability between studies making it difficult to draw normative conclusions [6]. This brief paper proposes that it is time for research in this area to move beyond gathering information about attitudes toward $\mathrm{AD}$ into constructing evidence that can predict how nurses might behave in this rapidly expanding legal environment. Nurses continue to require guidance in navigating the moral, legal and technical issues related to $\mathrm{AD}[7,8]$, and research relevance can be enhanced if we focus on what the nurse might do, and what factors shape that behaviour. There are at least two obstacles that have hobbled much research to date: poorly defined behaviour that is classified as "participation", and the regular juxtaposition of attitude with participatory behaviour.

\section{DISCUSSION}

What behaviour are we talking about when we research nursing participation in $\mathrm{AD}$ ? An assisted death is a rare event, with rates of reported incidents ranging from $0.3 \%-4.6 \%$ of non-sudden deaths in jurisdictions where some form of AD is legal [9]. Depending on what is meant by participation, the direct involvement of nurses
Quick Response Code:

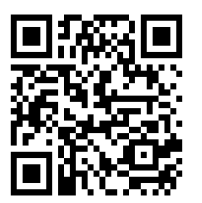

Address for correspondence: Michael Wilson, Faculty of Health and Medical Sciences (Nursing), University of Adelaide, Australia

Received: October 10, 2019 Published: December 04, 2019

How to cite this article: Michael W. Understanding Nurses' Intentions to Respond to Requests for Assisted Dying. 2019 - 1(3) OAJBS.ID.000124. DOI: 10.38125/OAJBS.000124 
can be even rarer. In the Netherlands nursing administration of lethal drugs is decreasing as doctors are no longer allowed to delegate that task [10]; in the Australian state of Victoria where AD by self-administration is legal, a health professional can directly assist a person to ingest the drug only by special permit [11]. On the other hand, nursing participation in Canada can be comprehensive, including a prescribing role for nurse practitioners but also a central role in its organisation by registered nurses $[12,13]$.

Regardless of how participation has been framed, many studies have identified participation as a function of attitude toward the practice. Attitude is generally understood as a global evaluation of the goodness or usefulness of an object or behaviour [14], and we are often left with the idea that attitude toward AD is linked with a willingness to participate in processes related to the service. Social and cognitive psychology has demonstrated weak links between attitude and behaviour [15], but "willingness" is an unsatisfactory moderator between attitude and participation because it does not tell us what a nurse will do. Willingness is an effective response that has been portrayed as a binary, yes/no, decision to participate in this rare event.

These rare events are usually well-structured delegations for clinical procedures, but the first step toward any of those advanced processes is a much less structured personal response to a patient's request for $\mathrm{AD}$. A nurse is often the professional who receives the initial request, although rates vary by care setting [16-18]. The request and the response often occur in brief moments and in the context of pressured clinical workloads [19], yet the response can facilitate, delay or obstruct the patient's request. To borrow from the language of chaos theory, the outcome for the requesting patient has a sensitive dependence on this initial condition. The importance of this moment for future research is exemplified by the focus of the guidance for managing these discussions from the Royal College of Nursing [20] and the newly revised position of the American Nurses Association [21].

The relevance of research in this area can be enhanced by shifting attention to the increasingly frequent experience of responding to a request for $\mathrm{AD}$ and by measuring cognitive intention to respond. Intention suggests a mental rehearsal for what the nurse will do when presented with a request, and since there are many possible responses in that situation intention is more likely to be multidimensional instead of binary. Decades of behavioural research demonstrate that intention is the proximate determinate of behaviour [22] and can be the best predictor of the possible responses when presented with a patient's request.

The role of behavioural theories is well established in most areas of health research and quality improvement [23]. Stages of change models, for instance, guide many cognitive interventions to change health behaviours such a smoking cessation; the Theory of Planned Behaviour (TPB) has framed dozens of clinical interventions to predict compliance with practice standards (e.g., handwashing, cannulation, documentation). The application of behavioural theory to promote better end-of-life decisions is rare [24]; however, where it has been deployed, its most robust use concerns nurses' intentions to participate in $\mathrm{AD}$ [5].

Research by Lavoie [25] into nursing decision-making about $\mathrm{AD}$ highlights consideration for future research in this area: Intention is predicted by a complex of factors more significant than attitude alone. Apart from measures of legal and organizational requirements, work structures and collegial expectations. TPBbased studies typically find that including moral norm items strengthen the variance explained by the model [26]. This suggests that it is reasonable to operationalise attitude as a global evaluation of performing a behaviour, but that it is important to assess the underlying beliefs and values that shape the attitude that then predicts the intention to respond in a way.

\section{CONCLUSION}

The emergence of a testable holistic model to explain and predict often unseen nursing behaviours in end of life care where AD is a legal option is a significant development. We already understand the complexities of participating in $\mathrm{AD}$, and the role that attitude has in that process. Intentions, however, are more than a product of basic beliefs about the goodness of an action. Intentions to act are also formed by social, professional and ethical norms and of course by the constraints of time, organisational policy and the law. The usefulness of research in this area can be enhanced when it draws from a theoretical framework that can model the constellation of factors that have already been identified that shapes behavioural intentions.

\section{REFERENCES}

1. Verpoort C, Gastmans C, De Bal N, Dierckx de CB (2004) Nurses' attitudes to euthanasia: A review of the literature. Nurs Ethics 11(4): 349-365.

2. Berghs M, Dierckx de Casterle B, Gastmans C (2005) The complexity of nurses' attitudes toward euthanasia: a review of the literature. J Med Ethics 31(8): 441-446.

3. De Bal N, Gastmans C, Dierckx de CB (2008) Nurses' involvement in the care of patients requesting euthanasia: a review of the literature. Int J Nurs Stud 45(4): 626-644.

4. Quaghebeur T, Dierckx de CB, Gastmans C (2009) Nursing and Euthanasia: a review of argument-based ethics literature. Nurs Ethics 16(4): 466-486.

5. Vézina-Im LA, Lavoie M, Krol P, Olivier DAM (2014) Motivations of physicians and nurses to practice voluntary euthanasia: a systematic review. BMC Palliat Care 13(1): 20.

6. Nilstun T, Melltorp G, Hermerén G (2000) Surveys on attitudes to active euthanasia and the difficulty of drawing normative conclusions. Scand J Public Health 28(2): 111-116.

7. Terkamo MA, Kvist T, Kangasniemi M, Laitila T, Ryynänen OP, et al. (2017) Nurses' attitudes towards euthanasia in conflict with professional ethical guidelines. Nurs Ethics 24(1): 70-86.

8. Wilson M, Oliver P, Malpas PJ (2019) Nurses' views on legalising assisted dying in New Zealand: a cross-sectional study. Int J Nurs Stud 89: 116124.

9. Emanuel E, Onwuteaka PBD, Urwin JW, Cohen J (2016) Attitudes and Practices of Euthanasia and Physician-Assisted Suicide in the United States, Canada and Europe. JAMA 316(1): 79-90.

10. Francke AL, Albers G, Bilsen J, de Veer AJE, Onwuteaka PBD (2016) Nursing staff and euthanasia in the Netherlands. A nation-wide survey on attitudes and involvement in decision making and the performance of euthanasia. Patient Educ Couns 99(5): 783-789.

11.(2017) Government of Victoria. Voluntary assisted dying bill by explanatory memorandum. Vic. Bills Explan. Memo.

12. Li M, Watt S, Escaf M, Gardam M, Heesters A, Leary GO, et al (2017) Medical assistance in dying- implementing a hospital-based program in Canada. N Engl J Med 376(21): 2082-2088.

13. Pesut B, Thorne S, Grieg M, Fulton A, Janke R, et al. (2019) Ethical, policy and practice implications of nurses'experiences with assisted death: A Synthesis. ANS Adv Nurs Sci 42(3): 216-230.

14. Olson J, Zanna M (1993) Attitudes and attitude change. Annu Rev Psychol 44: 117-132. 
15. Ajzen I (2001) Nature and operation of attitudes. Annu Rev Psychol 52 27-58.

16. Denier Y, Gastmans C, de Bal N, Dierckx de CB (2010) Communication in nursing care for patients requesting euthanasia: a qualitative study. J Clin Nurs 19(23-34): 3372-3380.

17. Van Bruchem-Van de Scheur A van der Arend A, Wijmen FV, Huda HAS Ter Meulen R (2008) Dutch nurses' attitudes towards euthanasia and physician-assisted suicide. Nurs Ethics 15(2): 186-198.

18. Van Bruchem-van de Scheur GG, van der Arend AJG, Spreeuwenberg C, Abu SHH, Meulen RHJT (2007) Euthanasia and physician-assisted suicide in the dutch homecare sector: The role of the district nurse. J Adv Nurs 58(1): 44-52.

19. Elmore J, Wright DK, Paradis M (2016) Nurses' moral experiences of assisted death: A meta-synthesis of qualitative literature. Nurs Ethics 25(8): 955-972.

20. (2016) When someone asks for your assistance to die: RCN guidance on responding to a request to hasten death $\left(2^{\text {nd }}\right.$ edn $)$. Royal College of Nursing.
21. (2019) The nurse's role when a patient requests medical aid in dying. American Nurses Association (ANA).

22. Ajzen I, Madden TJ (1986) Prediction of goal-directed behaviour: Attitudes, intentions, and perceived behavioral control.J Exp Soc Psychol 22(5): 453-474.

23. Godin G, Bélanger GA, Eccles M, Grimshaw J (2008) Healthcare professionals' intentions and behaviours: A systematic review of studies based on social cognitive theories. Implement Sci 3: 36

24. Scherrens AL, Beernaert K, Robijn L, Deliens L, Pauwels NS, et al. (2018) The use of behavioural theories in end-of-life care research: A systematic review. Palliat Med 32(6): 1055-1077.

25. Lavoie M, Godin G, Vezinaim L, Blondeau D, Martineau I, et al. (2016) Psychosocial determinants of nurses' intention to practise euthanasia in palliative care. Nurs Ethics 23(1): 48-60.

26. Godin G, Conner M, Sheeran P (2005) Bridging the intention-behaviour gap: The role of moral norm. Br J Soc Psychol 44(pt 4): 497-512. 